\title{
Angiotensin converting enzyme inhibition: from viper to patient
}

\author{
Michel Komajda, Marie-Catherine Wimart
}

Service de

Cardiologie, Hôpital

Pitié-Salpétrière, 47-83 Boulevard de l'hôpital, 75651 Paris Cedex 13, France M Komajda

M-C Wimart

Correspondence to: Professor Komajda

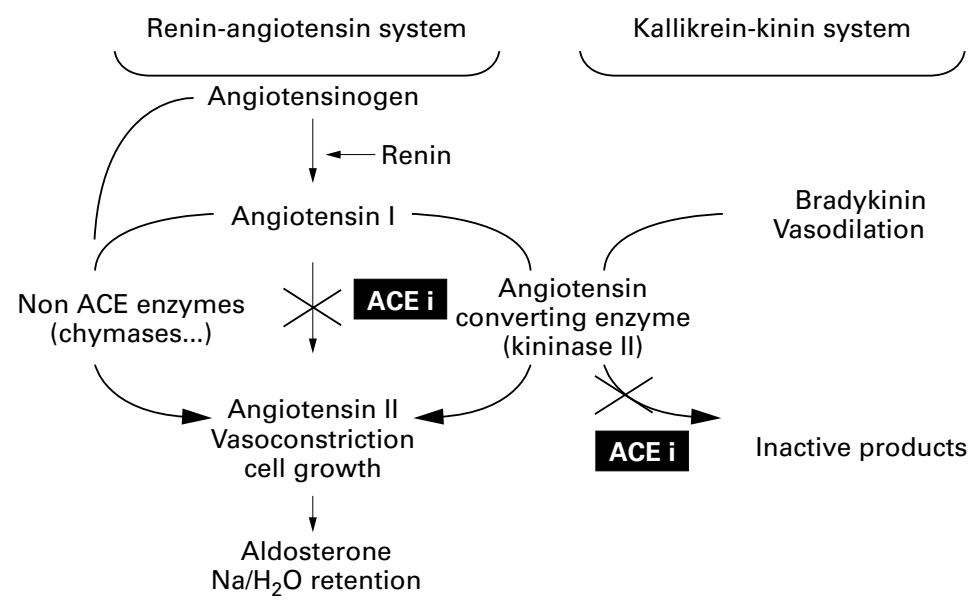

Figure 1 Role of ACE inhibitors in the renin-angiotensin aldosterone system. alternative pathways exist such as the kinase pathway, which bypass ACE in the generation of angiotensin II. Also, the renin-angiotensin system (RAS) is not only found in the circulation, but also in tissues. All components of the cascade are found in a series of tissues, including the heart and the vascular wall.

With the widespread actions of RAS, it is not surprising that many potential beneficial effects
The story of angiotensin converting enzyme (ACE) inhibitors started approximately 50 years ago, when it was discovered that human plasma incubated with the venom of the Brazilian viper, Bothrops fararaca, generated a hypotensive compound. This discovery quickly led to the characterisation of the active principle of the venom by Fereira and Greene as a family of peptides, which were named bradykinin potentiating factors as they selectively improved the biological effects of bradykinin. The observation was then made by Vane that these peptides could also block the conversion of angiotensin I into angiotensin II via the angiotensin converting enzyme. The active peptides were isolated and teprotide became the first ACE inhibitor to be evaluated clinically. The search for an orally active compound that was sufficiently potent to be developed as an antihypertensive drug resulted in the design and development of captopril, which entered first phase clinical studies in 1977.

ACE has a key role in two different physiological pathways (fig 1). One is in the synthesis of angiotensin II, which has vasoconstrictive properties, promotes retention of sodium and water, and promotes cell growth. The second is in the breakdown of bradykinin into inactive peptides. Bradykinin is a potent vasodilator through the synthesis of nitric oxide and vasodilatory prostaglandins. Importantly,
Table 1 ACE inhibitor pharmacological properties

\begin{tabular}{ll}
\hline $\begin{array}{l}\text { Sulfhydryl group } \\
\text { Non-prodrug }\end{array}$ & $\begin{array}{l}\text { captopril-zofenopril } \\
\text { captopril-lisinopril-moexipril } \\
\text { Short half life }\end{array}$ \\
$\begin{array}{l}\text { captopril }(2-3 \mathrm{~h}) \text {-perindopril }(5 \mathrm{~h}) \\
\text { quinapril }(3 \mathrm{~h})\end{array}$ \\
$\begin{array}{l}\text { captopril-cilazapril-enalapril } \\
\text { lisinopril-perindopril }\end{array}$ \\
$\begin{array}{l}\text { captopril-cilazapril-perindopril } \\
\text { Renal elimination }\end{array}$ & $\begin{array}{l}\text { captopril-cilazapril-enalapril } \\
\text { lisinopril-perindopril-quinapril } \\
\text { ramipril-benazepril-trandolapril } \\
\text { fosinopril }\end{array}$ \\
\hline
\end{tabular}

have been ascribed to ACE inhibitors including improvement of endothelial function, an antihypertensive effect, and a reduction in left ventricular mass. There are currently 11 different ACE inhibitors available and, interestingly, there are still a further five molecules under investigation. These agents differ considerably in terms of their pharmacological properties (table 1).

ACE inhibitors can be used in the following areas:

- hypertension;

- heart failure/asymptomatic left ventricular dysfunction;

- acute/post-myocardial infarction;

- diabetic complications, including nephropathy and retinopathy;

- non-diabetic nephropathy.

It is very likely that, following the results of the HOPE study, a new indication for coronary or vascular primary prevention in high risk patients will be introduced. ${ }^{1}$

\section{Hypertension}

Hypertension was the original indication for ACE inhibitors. Two key studies have recently been published which examine the role of ACE inhibitors in hypertension: UKPDS and CAPPP. $^{23}$ In UKPDS, patients with type II diabetes and concomitant hypertension were randomised either to very active antihypertensive treatment (with captopril or atenolol) or to a less stringent management strategy. Active care produced a significant decrease in both micro- and macrovascular events in this population. $^{2}$

The CAPPP trial enrolled more than 10000 patients and studied the effect of captopril compared to more traditional strategies ( $\beta$ blockers and diuretics). The two strategies were equivalent on the composite end point of fatal and non-fatal myocardial infarction, stroke, and other cardiovascular deaths. There was a significant increase in the risk of stroke in the captopril group, although overall cardiovascular mortality favoured captopril. ${ }^{3}$ The recently completed STOP-Hypertension-2 study provides further evidence of the role of ACE 
inhibitors in the treatment of hypertension. ${ }^{4}$ In addition, ALLHAT, a large, ongoing trial which includes over 40000 patients, will evaluate the difference between various therapeutic strategies on composite cardiovascular end points in hypertensive patients.

Importantly, it has been shown that left ventricular hypertrophy ( $\mathrm{LVH})$ is an independent predictor of mortality; therefore one of the major goals of current antihypertensive treatments is to reduce LVH. In a recent metaanalysis it was shown that ACE inhibition produced a $15 \%$ reduction in left ventricular mass, which was greater than that achieved by three other antihypertensive classes investigated in the analysis. ${ }^{6}$

\section{Heart failure}

A wide spectrum of heart failure patients, from New York Heart Association (NYHA) functional class II to IV, benefit from ACE inhibitor treatment. A number of studies have demonstrated a reduction in mortality in patients treated with ACE inhibitors: CONSENSUS 1 ( $40 \%$ reduction); SOLVD treatment $(16 \%$ reduction); V-HeFT II (28\% reduction)..$^{7-9}$ Moreover, it was shown in the ATLAS trial that there was a non-significant trend towards reduced mortality with high dose lisinopril when compared with patients taking a low dose (fig 2). The SOLVD-treatment, ATLAS, and SAVE trials have also shown that ACE inhibitors are able to reduce the hospitalisation rate of heart failure patients by a significant $20-25 \% .^{81011}$

\section{Myocardial infarction}

There are two subsets of myocardial infarction patients who benefit from ACE inhibitors: acute myocardial infarction patients and postmyocardial infarction patients who have signs of cardiac damage. In the ISIS-4 study, use of ACE inhibitors in patients with acute myocardial infarction resulted in a $7 \%$ mortality reduction at five weeks and in the GISSI-3 study, an $11 \%$ reduction at six weeks. ${ }^{12}{ }^{13}$

ACE inhibitors also demonstrate benefits in post-myocardial infarction patients who have either left ventricular dysfunction (SAVE) or overt heart failure (AIRE). Data from the SAVE trial, among patients with left ventricular dysfunction after an acute myocardial infarction, demonstrate a reduction in mortality from cardiovascular causes of $21 \%$ with ACE inhibitor treatment. ${ }^{11}$

\section{Diabetic nephropathy}

ACE inhibitors have been demonstrated to be beneficial in diabetic nephropathy in at least two studies. In the study by Lewis and colleagues, a combined end point of death and need for dialysis or transplantation was reduced by $50 \%$ in high risk patients with type 1 diabetes. ${ }^{14}$ In the EUCLID study, using lisinopril in normotensive type 1 diabetic patients, there was a $20 \%$ reduction in urinary albumin excretion. ${ }^{15}$

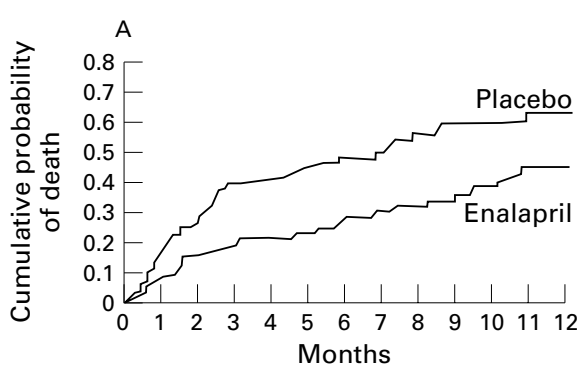

Placebo n:126 $10278 \quad 63 \quad 59 \quad 53 \quad 47 \quad 42 \quad 34 \quad 30 \quad 24 \quad 18 \quad 17$

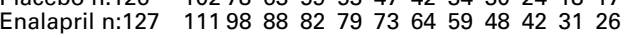
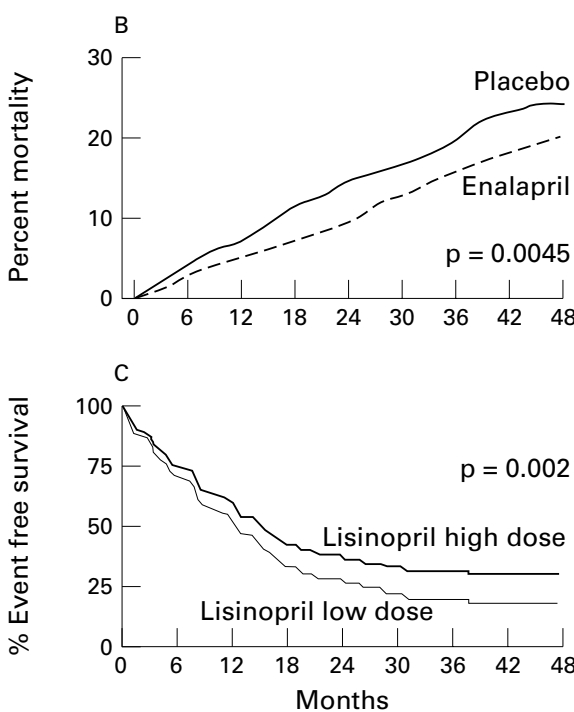

Figure 2 There is an early divergence between the two curves in favour of the ACE inhibitor in (A) CONSENSUS 1 (heart failure mortality), (B) SOLVD (mortality caused by progressive heart failure), and (C) ATLAS (all cause mortality plus hospitalisation for any reason).

\section{Non-diabetic nephropathy}

ACE inhibitors have also been demonstrated to prevent the progression of renal insufficiency in patients without diabetes. Two studies (with benazepril and ramipril) have each demonstrated a very impressive reduction in the risk of progressive renal insufficiency of more than $50 \% \cdot{ }^{16}{ }^{17}$ In one of the studies, the beneficial effect was observed even after correction for blood pressure. This suggests that the nephroprotective effect of ACE inhibitors might be independent of the hypotensive effect.

\section{Diabetic retinopathy}

In diabetic retinopathy, ACE inhibitors have also been shown to decrease the progression of the disease, both in type 1 and type 2 diabetic patients. In the EUCLID study, lisinopril reduced the risk of retinopathy progression by one grade by $50 \%(p=0.02)$, and in the UKPDS the outcome was reduced by $37 \% .^{2}{ }^{18}$

\section{Unanswered questions}

Despite the wealth of evidence that exists for the efficacy of ACE inhibitors in the management of a range of conditions, there remain unanswered questions.

For example, there are interesting experimental data suggesting that, at least for the regression of left ventricular hypertrophy, the 


\section{Trial acronyms}

ALLHAT: Antihypertensive and Lipid Lowering to prevent Heart Attack Trial

ATLAS: Assessment of Treatment with Lisinopril and Survival

CAPPP: Captopril Prevention Project

CHARM: Candesartan in Heart failureAssessment of Reduction in Mortality and morbidity

CONSENSUS-1: Co-Operative North Scandinavian Enalapril Survival Study

ELITE II: Evaluation of Losartan In The Elderly-2

EUCLID: EUrodiab Controlled trial of Lisinopril in Insulin dependent Diabetes mellitus

GISSI-3: Gruppo Italiano per lo Studio della Sopravvivenza nell'Infarcto miocardico

HOPE: Heart Outcomes Prevention Evaluation

ISIS-4: Fourth International Study of Infarct Survival

SAVE: Survival And Ventricular Enlargement

SOLVD: Studies Of Left Ventricular Dysfunction

STOP-Hypertension-2: Swedish Trial in Old Patients with Hypertension-2 study UKPDS: UK Prospective Diabetes Study V-HeFT II: Vasodilator Heart Failure Trial II

inhibition of bradykinin breakdown may be important. However, there are very little clinical data available, so this question remains open. Moreover, there are contradictory results in the literature regarding the importance of the escape pathway. An in vitro study showed that kinase-like enzyme activity was predominant over ACE activity in both the heart and the aorta. ${ }^{19}$ Conversely, in an in vivo study in normotensive subjects the administration of enalapril was able to inhibit the pressure response to angiotensin I intravenous infusion, and to block totally the conversion of angiotensin I into angiotensin $\mathrm{II}^{20}{ }^{20}$ Therefore, the clinical importance of the escape pathway is not yet fully understood.

Interest has also recently focused on whether better responders to ACE inhibitors can be identified. Probably, the black population are not suitable patients for antihypertensive treatment with ACE inhibitors. The diabetic population, by contrast, benefits greatly from ACE inhibitor treatment. In the CAPPP study ACE inhibition was able to reduce the occurrence of cardiovascular events by more than $40 \%$ in the diabetic patient. ${ }^{3}$ In the GISSI-3 trial there was a threefold reduction in mortality in diabetic patients as opposed to the total population. ${ }^{10}$

A potential new avenue for identifying suitable patients is the use of pharmacogenetics. It is possible that, in the future, the identification of new polymorphisms will allow the selection of better responders to ACE inhibitors. For example, the $\mathrm{D} / \mathrm{D}$ genotype is associated with a greater elevation of blood pressure following angiotensin I intravenous infusion and a greater response to intravenous enalaprilat. This genotype is also associated with higher levels of cardiac ACE activity.

\section{The future}

There is much speculation as to whether angiotensin II receptor blockers will challenge ACE inhibitors in the treatment of hypertension. Following the results of the ELITE II trial, ACE inhibition remains the gold standard as first line treatment for heart failure. ${ }^{21}$ There is also interest in possible new indications for ACE inhibitors. Ongoing trials are assessing whether ACE inhibitors are beneficial in high risk patients. This may result in a new indication of cardiovascular prevention in these high risk populations. Another important issue is whether the combination of ACE inhibition with $\mathrm{AT}_{1}$ blockade has benefits. There is an ongoing trial programme, CHARM, which compares the combination of candesartan and enalapril to enalapril alone in patients with heart failure..$^{22}$ Another potential new avenue is the development of dual inhibitors which block both ACE and the neutral endopeptidase. With such strong evidence demonstrating the benefits of ACE inhibition it is very disappointing that there is still under use of this class of medication in clinical practice.

1 The Heart Outcomes Prevention Evaluation Study Investigators. Effects of an angiotensin-converting-enzyme inhibitor, ramipril, on cardiovascular events in high-risk patients. N Engl F Med 2000;342:145-53.

2 UK Prospective Diabetes Study Group. Tight blood pressure control and risk of macrovascular and microvascuar complications in type 2 diabetes: UKPDS 38. BMF 1998;317:703-13.

3 Hansson L, Lindholm LH, Niskanen L, et al. Effect of angiotensin-converting-enzyme inhibition compared with conventional therapy on cardiovascular morbidity and mortality in hypertension: the Captopril prevention project (CAPPP) randomized trial. Lancet 1999;353:611-16.

4 The STOP-Hypertension-2 Study Group. Randomised trial of old and new antihypertensive drugs in elderly patients: cardiovascular mortality and morbidity in the Swedish trial in old patients with hypertension-2 study. Lancet 1999;354: in old patie.

5 Elliot WJ. ALLHAT: the largest and most important clinical trial in hypertension ever done in the USA. Antihypertensive and lipid lowering to prevent heart attack trial. $A m \mathcal{F}$ Hypertens 1996;9(4)Pt 1:342-60

6 Dahlof B, Pennert K, Hansson L. Reversal of left ventricular hypertrophy in hypertensive patients. A meta-analysis of 109 treatment studies. Am $\mathcal{F}$ Hypertens 1992;5:95-110.

7 The CONSENSUS Trial Study Group. Effects of enalapril on mortality in severe congestive heart failure: results of the co-operative north Scandinavian enalapril survival study (CONSENSUS). N Engl F Med 1987;316:1429-35.

8 The SOLVD Investigators. Effect of enalapril on survival in patients with reduced left ventricular ejection fractions and congestive heart failure. N Engl f Med 1991;325:293-302.

9 Cohn JN, Johnson G, Ziesche S, et al. A comparison of enalapril with hydralazine-isosorbide dinitrate in the treatment of chronic congestive heart failure. N Engl F Med 1991;325: of chron 303 . 10 .

10 The ATLAS Study Group. Comparative effects of low and high doses of the angiotensin-converting-enzyme inhibitor, lisinopril, on morbidity and mortality in chronic heart failure. Circulation 1999;100:2312-18.

11 Pfeffer MA, Braunwald E, Moye LA, et al. Effect of captopril on mortality and morbidity in patients with left ventricular dysfunction after myocardial infarction. $N$ Engl Med 1992; 327:669-77.

12 ISIS-4 Collaborative Group. ISIS-4: a randomized factorial trial assessing early oral captopril, oral mononitrate, and intravenous magnesium sulphate in 58050 patients with suspected acute myocardial infarction. Lancet 1995;345: 669-85.

13 Gruppo Italiano per lo Studio della Sopravvivenza nell'Infarto Miocardico. GISSI-3: effects of lisinopril and transdermal glyceryl trinitrate singly and together on 6 -week mortality and ventricular function after acute myocardial infarction. Lancet 1994;343:1115-22.

14 Lewis EJ, Hunsicker LG, Bain RP, et al. The effect of angiotensin-converting-enzyme inhibition on diabetic nephropathy. N Engl f Med 1993;329:1456-62. 
15 The EUCLID Study Group. Randomised placebo controlled trial of lisinopril in normotensive patients with insulin dependent diabetes and normoalbuminuria or microalbuminuria. Lancet 1997;349:1787-92.

16 Locatelli F, Carbarns IR, Maschio G, et al. Long-term progression of chronic renal insufficiency in the AIPRI extension study. The angiotensin-converting-enzyme inhibition in progressive renal insufficiency study group. Kidney Int Suppl 1997;63:S63-6.

17 The GISEN Group. Randomised placebo-controlled trial of effect of ramipril on decline in glomerular filtration rate and risk of terminal renal failure in proteinuric, nondiabetic nephropathy. Lancet 1997;349:1857-63.

18 Chaturvedi N, Sjolie AK, Stephenson JM, et al. Effect of lisinopril on progression of retinopathy in normo tensive people with type 1 diabetes. Lancet 1998;351:28-

19 Akasu M, Urata H, Kinoshita A, et al. Differences in tissue angiotensin II-forming pathways by species and organs in vitro. Hypertension 1998;32:514-20.

20 Danser A, M van Dijk, I Kroon, et al. Evidence for the functional importance of ACE-dependent in-situ angiotensin II generation in the human forearm [abstract]. Circulation 1999;100(suppl 1):548.

21 Topol E. ACE inhibitors still the drug of choice for heart failure. Lancet 1999; 354:1797.

22 Swedberg K, Pfeffer M, Granger C, Held P et al. Candesartan in heart failure - assessment of reduction in mortality and morbidity (CHARM): rationale and design. CharmProgramme Investigators. f Card Fail 1999;5:276-82. 